\title{
Comparing Simulated Carbon Budget of a Lei Bamboo Forest with Flux Tower Data
}

\author{
Xuehe Lu ${ }^{1}$, Hong Jiang ${ }^{1,2, *}$, Jinxun Liu ${ }^{3}$, Cheng Sun ${ }^{2}$, Ying Wang ${ }^{1}$, and Jiaxin Jin $^{1}$ \\ ${ }^{1}$ International Institute for Earth System Science, Nanjing University, Nanjing, China \\ ${ }^{2}$ State Key Laboratory of Subtropical Forest Science \& Zhejiang Provincial Key Laboratory of Carbon Cycling in Forest \\ Ecosystems and Carbon Sequestration, Zhejiang Agriculture and Forestry University, Zhejiang, China \\ ${ }^{3}$ Western Geographic Science Center, U.S. Geological Survey, CA, USA
}

Received 23 October 2012, accepted 13 January 2014

\begin{abstract}
Bamboo forest ecosystem is the part of the forest ecosystem. The distribution area of bamboo forest is limited, but in somewhere, like south China, it has been cultivate for a long time with human management. As the climate change has been take great effect on forest carbon budget, many researchers pay attention to the carbon budget in bamboo forest. Moreover cultivative management had a significant impact on the bamboo forest carbon budget. In this study, we modified a terrestrial ecosystem model named Integrated Biosphere Simulator (IBIS) according the management of Lei bamboo forest. Some management, like fertilization, shoots harvesting and organic mulching in winter, had been incorporated into model. Then we had compared model results with the observation data from a Lei bamboo flux tower. The simulated and observed results had achieved good consistency. Our simulated Lei bamboo forest yearly net ecosystem productivity (NEP) was $0.41 \mathrm{kgC} \mathrm{a}^{-1}$ of carbon, which is very close to the observation data $0.45 \mathrm{kgC} \mathrm{a}^{-1}$ of carbon. And the monthly simulated results can take the change of carbon budget in each month, similar to the data we got from flux tower. It reflects that the modified IBIS model can characterize the growth of bamboo forest and perform the simulation well. And then two groups of simulations were set to evaluate effects of cultivative managements on Lei bamboo forests carbon budget. And results showed that both fertilization and organic mulching had taken positive effects on Lei bamboo forests carbon sequestration.
\end{abstract}

Key words: Lei bamboo forest, Carbon budget, Flux tower, Ecological model

Citation: Lu, X., H. Jiang, J. Liu, C. Sun, Y. Wang, and J. Jin, 2014: Comparing simulated carbon budget of a Lei bamboo forest with flux tower data. Terr. Atmos. Ocean. Sci., 25, 359-368, doi: 10.3319/TAO.2014.01.13.01(TT)

\section{INTRODUCTION}

Globally terrestrial ecosystems absorb about $2.4 \pm 0.4$ $\mathrm{PgC}$ every year (Pan et al. 2011). Forests play a major role in global terrestrial carbon cycling. Bamboo forests are one of important forest types in the world which distributed in the tropical, subtropical, and warm temperate regions (generally between $46^{\circ}$ north and $47^{\circ}$ south). In China bamboo forest is distributed in 11 southern province and take about 48.5 millions $\mathrm{hm}^{2}$ which is $2.5 \%$ of China forest area and $39 \%$ of the world bamboo forest area (SFAPRC 2005). According to the statistic data obtained from the previous National Forestry Inventory, the area of bamboo forests in China has increased by $51.40 \%$. from 1970s to this century (Chen et

\footnotetext{
* Corresponding author

E-mail: jianghong_china@hotmail.com
}

al. 2009). About more than 2 million tons of bamboo shoots are consumed every year around the world (Kleinhenz and Midmore 2000) with approximately 1.3 million produced in China (Kunshan et al. 1997). Besides bamboo shoots, the application fields of bamboo is wide. Culms for timber or for paper pulp are the major products from bamboo forests. Total transactions of bamboo products have been estimated at US $\$ 4.5$ billion $^{-1}$. As the significant contribution of bamboo produces has been made to economy, bamboo forests has been cultivated widely in south of China. At mean while, multiple ecologic functions had been provided by bamboo forests in cultivation arers (Kleinhenz and Midmore 2001). Due to its great potential for rapid biomass production (Pearson et al. 1994; Scurlock et al. 2000), bamboo is a vital net carbon sink under global climate change (Isagi et al. 1997; Chen et al. 2009; Zhuang et al. 2011). Some researchers 
reported that bamboo forests, such as mao bamboo forest, have more efficient carbon sequestration than typical temperate forests, like Chinese fire and mason pine, in southern China (Zhou and Jiang 2004). The advantage of bamboo forest in carbon sequestration will let it makes an important role in future climate change.

Lei bamboo has a very high production rate both in fresh edible shoots (for food) and woody biomass. It is a widely cultivated species with high economic values in China and its distribution area has been expanding constantly during nearly fifty years, especially in Zhejiang province. The growth of Lei bamboo forests have their own characteristics. It usually begins new shoot growth in the middle of February. After about a two-month rapid growing, the Lei bamboo shoot growth will slow down by the end of April or early May. At the same time, Lei bamboo leaves will be fully spread and leaf area index (LAI) reaches maximum. In the middle of May, the growing of young bamboo will stop. From June to August, Lei bamboo forest is general under heat and light stress and do not have obvious growth on aboveground biomass. Another growth peak will be reached in the September and October. During that time, a lot of organic matters are preserved into the bamboo rhizome system that can be used for new bamboo growth in the next year (Jiang et al. 2006). Futher more, the managements of Lei bamboo forests also have their own characteristics. There are several key management activities for Lei bamboo that differ from other forest management. One is improving ground surface temperature in winter. Organic mulching with straw $(15-20 \mathrm{~cm})$ and bran $(10 \mathrm{~cm})$ are usually implemented in late November or early December. Because of the mulching, soil temperature in winter time is typically $2^{\circ}-5^{\circ} \mathrm{C}$ degrees higher than that of uncovered soil (Qg et al. 1995; Huang et al. 2007). Until April of the following year, the bran is recollected and the straw is almost decomposed totally, Organic mulching not only increases soil temperature in winter, but also provides amount of soil nutrient for bamboo growthing. Another special management activity is the harvesting. Lei Bamboo harvesting both includes edible fresh shoot and matured bamboo. Edible fresh shoots are harvested once a year in spring. While mature bamboo harvested every three years in winter. And fertilization in Lei bamboo forests are applied multi-times each year (Zhou et al. 2011).

Under the background of global change, the effects of Lei bamboo forests on ecosystems, especially in carbon cycling had been focused by some researches as distribution areas have been expanding constantly. The effects of winter organic mulching on soil carbon had been studied and the results shown that long-term application of organic mulch over winter increased total soil organic C ( $\mathrm{Li}$ et al. 2010; Zhou et al. 2011) and litterfall decomposition rate (Zhang et al. 2013). Currently, the many researches of Lei bamboo forests' soil carbon pool are sufficient relatively. However the researches of the wholly carbon cycles in Lei bamboo forests are rare. Measurement of flux tower is an effective way to research forest carbon cycles. Using the theory of eddy covariance, flux tower measurement is usually considered as an accurate method and widely used in monitoring ecosystem carbon flux (Cleugh et al. 2007; Reichstein et al. 2007). Besides fluxe tower measurement, model simulation is an another approache to study forests carbon cycles. In the past few decades, many terrestrial ecosystem models had been used to simulate carbon cycles in different scales (Cox et al. 2000; Cramer et al. 2001; Ju et al. 2007) and the IBIS model was one of them. IBIS is a process based model which was developed by Foley et al. (1996) in University of Wisconsin (Foley et al. 1996; Kucharik et al. 2000). It had been successfully used in some local, regional and global carbon cycleing studies (Delire and Foley 1999; Costa and Foley 2000; E1 Maayar et al. 2001; Ramankutty et al. 2002). And It had been also apply to water cycling studies and coupling effects of water and carbon studies (Zhu et al. 2010). Moreover researchers had compared IBIS outputs with eddy-covariance flux tower measurement and the results were satisfactory (Kucharik et al. 2000; E1 Maayar et al. 2001).

In this study we attempted to midificate IBIS model and simulate carbon cycling in Lei bamboo forest. As the intensive management of Lei bamboo forests, the original IBIS model need somo improvement to make it siutable to Lei bamboo forest. The main management of Lei bamboo forests include shoots harvesting, fertilization, thinning, and organic mulching. Model schema should incorporate these major managements. And then the simulated results had been validated by some previous studies and flux tower measurement. At last some managements effects on Lei bamboo forests carbon cycles had been accessed by a series of model simulations.

\section{METHOD}

\subsection{Carbon Flux Measurement}

In order to research the carbon cycling in Lei bamboo forest, a 20-meter eddy flux tower had been built in 2010 in Zhejiang, China $\left(30^{\circ} 28^{\prime} 34.5^{\prime \prime} \mathrm{E}, 119^{\circ} 40^{\prime} 25.7^{\prime \prime} \mathrm{N}\right)$. A series of meteorological variables and $\mathrm{CO}_{2}$ flux data were collected in Lei bamboo forests (Fig. 1). Carbon flux measurement had been done in seven different height level of flux tower. In each level, Infrared Ray Gas Analyzer (IRGA) had been installed to observate $\mathrm{CO}_{2}$ concentration. And the turbulence sensors are mainly a 3-D Sonic Anemo-Thermometer (SAT) for wind and temperaturein installed at the top of flux tower. The measurement of flux tower began in the late of 2010 and it had been collected valid data more than one year. And we used EdiRe developed university of Ediburgh to process flux data. Although the observation frequency of flux tower is high, we only used monthly average carbon flux data in our study in order to compare with IBIS simulated results. 


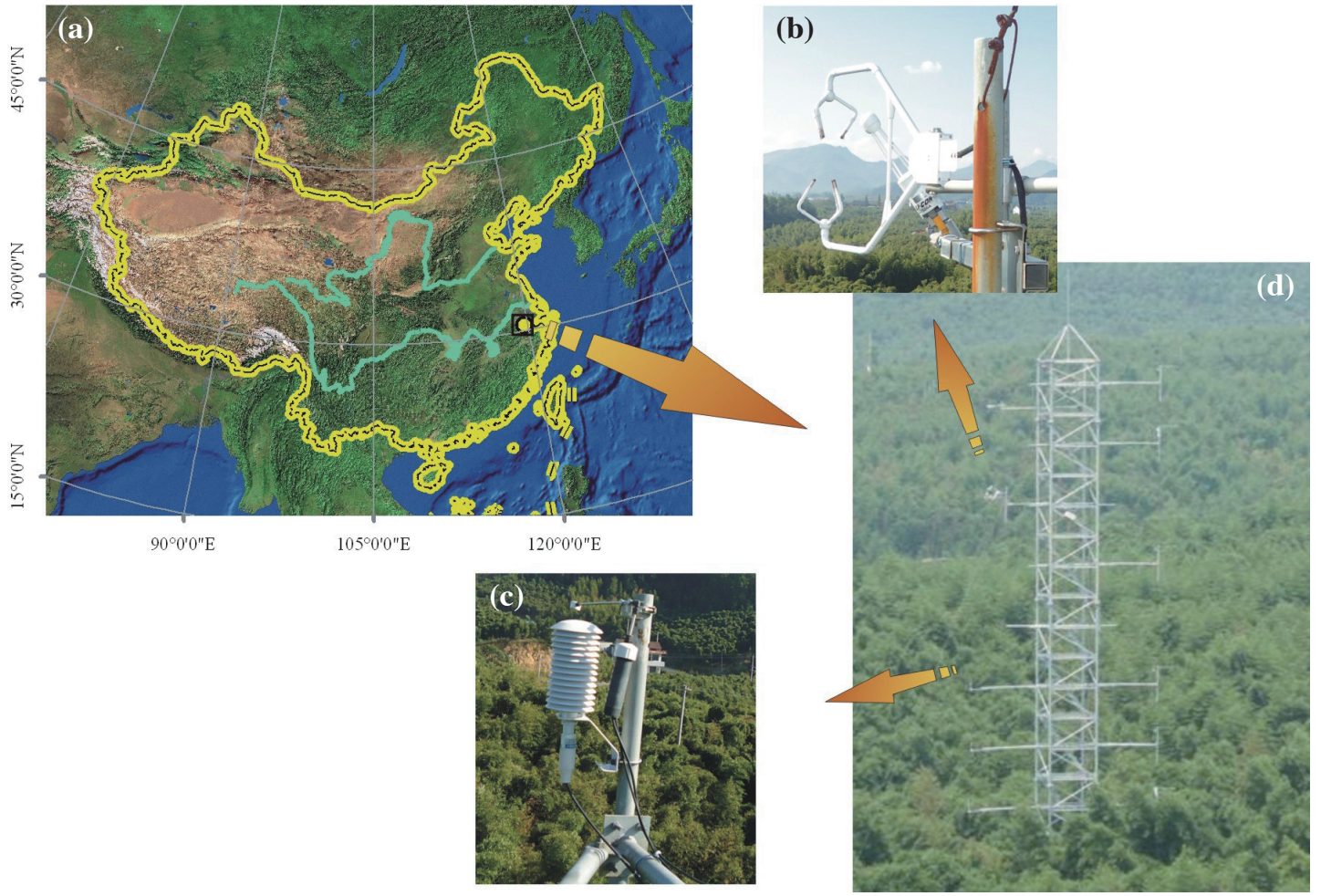

Fig. 1. The location of flux tower in the south of China. (a) The location of flux tower in China; (b) is 3-D Sonic Anemo-Thermometer (SAT); (c) Infrared Ray Gas Analyzer (IRGA); (d) flux tower overview.

\subsection{Carbon and Nitrogen Cycling in IBIS Model}

IBIS model is land surface process based model driven by meteorological data. It describes the process of ecosystem carbon and nitrogen cycles and important outputs include NPP, NEP, biomass, soil carbon, evaporation, nitrogen up take, etc. Liu et al. (2005) had incorporated a nitrogen cycling module in the IBIS model. In that module, photosynthesis, allocation of net primary productivity (NPP) and carbon cycling in the soil are control by nitrogen content in the ecosystem. In our study, we used this version of IBIS model.

Vegetation photosynthesis was characterized by Farque equation in IBIS model (Farquhar and Sharkey 1982). And the maximum photosynthetic velocity was controled by leaf avilable nitrogen [Eq. (1)].

$V m=\left(B_{V_{\max }} / B_{L}\right) \times V_{\max }$

$B_{V_{\max }}$ is the optimal C:N of foliar, at which the maximum photosynthetic rate $\left(V_{\max }\right)$ will be reached. $B_{L}$ is the actual foliar C:N and $V m$ is the actual photosynthetic rate. If nitrogen shortage in foliar, the actual foliar C:N $\left(B_{L}\right)$ will increase and it will make $V_{\max }$ decline. In IBIS model, this function indicate the feedback of nitrogen on photosynthesis.

Gross primary productivity of photosynthesis is com- sumed by autotrophic resipiration [Eq. (2)]. And then NPP can be caculated. In addition to comsumption of heterotrophic resipiration, net ecosystem productivity can be calculated [Eq. (3)]. The resipiration of vegetation is affected by environment factors. In this study, the effects of soil temperature on resipiration need to note specially in Eq. (4) as it is important to organic mulching inWinter in Lei bamboo forests.

$N P P=G P P-R a_{l}-R a_{w}-R a_{r}$

$N E P=N P P-R h$

$R a_{r}=$ Rroot $\times$ Cbiowr $\times F_{b}($ tsoi $)$

$N P P$ is net primary productivity, GPP is gross primary productivity. $R a_{l}, R a_{w}$, and $R a_{r}$ is foliar, wood and root respiration, respectively. $N E P$ is net ecosystem productivity. $R h$ is heterotrophic resipiration. Rroot is the fixed root respiration rate and Cbiowr is the biomass of root. tsoi is soil temperature. $F b(t s o i)$ is a function which can adjust the root respiration rate by $t s o i$.

Photosynthetic products allocate to different parts of vegetation after photosynthesis. And the carbon accumulates to leaf, wood and root biomass. In order to reflect the complete process of vegetation growth, a phenological module 
was integrated into the IBIS model. The growth and litter of leaves and fine root are controled by phenological module which is driven by climate data. And then the carbon and nitrogen in litterfall turn into soil carbon and nitrogen pools through by decomposition. In IBIS model, decomposition is affected by many environment factors such as soil temperature and the fequations are listed in Eqs. (5), (6), and (7).

$d_{s}=$ factor $\times$ moist

moist $=$ Fm $($ tsoi, pore, water,$\cdots)$

factor $=F f(t s o i)$

$d_{s}$ is the decomposition rate in soil carbon pools. It is relate to a calculate factor, factor and soil moisture, moist. In IBIS model, the calculation of moist is related to many variables including soil temperature, tsoi. At the same time, factor also have relationship with soil temperature.

About nitrogen feedback on decomposition can used the follow functions to describe.

$C_{x}= \begin{cases}d_{s} y_{i j} K_{i} p K_{I} C_{i}, & \delta_{i j} \leq 0 \\ d_{s} y_{i j} K_{i} p K_{M} C_{i}, & \delta_{i j}>0\end{cases}$

$C_{x}$ is the actual decomposition rate and it is controlled by some control factors. $d_{s}, y_{i j}, K_{i}, C_{i}$ belong to the original IBIS model, of which $d_{s}$ is the coefficient representing soil moisture and temperature effects on decomposition, $C_{i}$ is the carbon pool, $y_{i j}$ is the yield coefficient when $C_{i}$ is transferred from source $i$ to target $j$ and $K_{t}$ is the fixed base decomposition rate of each SOM pool. $p$ is a factor to control SOM decomposition fast or low due to soil carbon situation. $K_{I}$ and $K_{M}$ are two new modified factors incorporated into IBIS model and they are controlled by available nitrogen in soil [Eqs. (9) and (10)].

$K_{M}= \begin{cases}1.0-\left(N_{M}-N_{M_{\max }}\right) / N_{M_{\max }} & \text { (a) } \\ 1.0 & \text { (b) } \\ 1.0+\left(0.5 N_{M_{\max }}-N_{M}\right) / N_{M_{\max }} & \text { (c) }\end{cases}$

$K_{I}=0.8+0.2 N_{M} / N_{M_{\max }}$

$N_{M_{\max }}$ is maximum available nitrogen in soil, in IBIS model it is set to $2 \mathrm{~kg} \mathrm{~N} \mathrm{~m}^{-2} . N_{M}$ is the actual available nitrogen in soil. The calculation of $K_{M}$ and $K_{I}$ are depend on soil nitrogen conditions: (a) $N_{M} \geq N_{M_{\max }}$, (b) $0.5 N_{M_{\max }}<N_{M}<N_{M_{\max }}$, (c) $N_{M} \leq 0.5 N_{M_{\max }}$.

\subsection{Model Modification}

In order to simulate the carbon dynamics of Lei bamboo forest, a number of modifications in IBIS have been made. The main changes include the following three parts.

\subsubsection{Photosynthesis}

For nearly fifty years, Lei bamboo is widely cultivate in south of China, especially in Zhejiang province. Some researchers reported that Lei bamboo's net photosynthetic rate was about $14 \mathrm{umolCO}_{2} \mathrm{~m}^{-2} \mathrm{~s}^{-1}$ (Jin et al. 2000). As the maximum photosynthetic rate had been used in process of photosynthesis in IBIS model, the net photosynthetic rate can not been used directly. The differents between them are that the maximum photosynthetic rate include leaf resipiration rate. However, the maximum photosynthetic rate of Lei bamboo has not been reported yet. As the Lei bamboo's net photosynthetic rate is similar to typical evergreen broadleaf forest (Landsberg and Sands 2010), so we assume that Lei bamboo's maximum photosynthetic rate is equal to the maximum photosynthetic rate typical evergreen broadleaf forest in IBIS model $\left(45 \mathrm{umolCO}_{2} \mathrm{~m}^{-2} \mathrm{~s}^{-1}\right)$.

\subsubsection{A New Carbon Pool}

Lei bamboo forests have distinctive features of growth in spring. The traditional growth process in IBIS model can not characterize Lei bamboo forests well. So the modifications had been implemented. A new carbon pool called cpstore had been integrated into IBIS model. As the Fig. 2 shown, the role of cpstore is temporary storage of NPP. In summer, autumn, and winter patial NPP had been set to storage in cpstore insteed of in biomass. But in early sprint patial carbon storaged in cpstore had been used to the growth

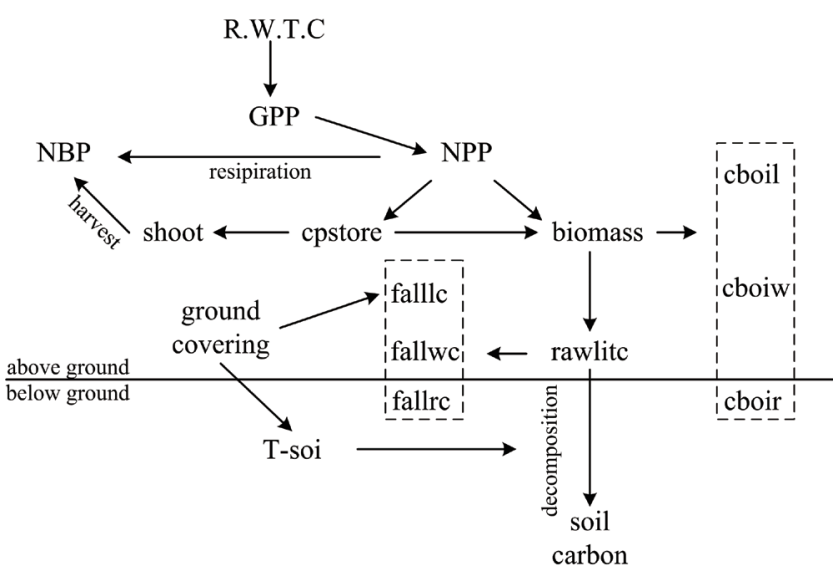

Fig. 2. The diagram of new carbon flow in IBIS model. GPP is gross primary productivity. NPP is net promary productivity. NBP is net biome productivity. Cpstore is the new carbon pool we added to IBIS model. Cbiol, cbiow and cboir are biomass in leaf, wood and root, respectively. Falllc, fallwc and fallrc are literfall carbon in leaf, wood and carbon respectively. T-soi is soil temperature. 
of shoot. As the bamboo shoots growing season came to the end in early May, carbon in cpstore had not been translated into shoot. And the rest of caronb in cpsotre had been changed into leaf in two weaks.

\subsubsection{Shoot Harvest and Bamboo Forests Thinning}

In the management of bamboo forests, fresh bamboo shoots harvest in spring and bamboo forests thinning are two important parts. In our modifications, a harvest moudle had been set up to simulate these parts. According to the actual bamboo harvest data, we set Lei bamboo shoot was harvested $1.1 \mathrm{kgC} \mathrm{m}^{-2} \mathrm{yr}^{-1}$ in February, March, April in IBIS model. In order to maximize economic benefits, when the age of bamboo is more than 6 it will be thinning. In IBIS modle, the age of forests were not considered. So we assume that about $16.7 \%$ of Lei bamboo forests' above biomass are harvested every year.

\subsubsection{Fertilization and Organic Mulching}

Fertilization and organic mulching are two important managements in the growth of bamboo forests. Fertilization are generally three times a year and the amount and types of fertilizer are different in each fertilization. As the nitrogen cycling modification of Liu et al. (2005), the effect of nitrogen fertilizer on Lei bamboo growth can be simulated. Due to the volatilization and leaching, the actual nitrogen fertilizer into ecosystems is difficult to estimate in current verson of IBIS model. However, nitrogen fertilization reduces nitrogen limiting effect on the ecosystem.carbon assimilation. We supplied nitrogen fertilizer as ecosystem demanded to minimize the effect of nitrogen limiting.

In order to promote time of shoots germination early, organic mulching has been used in the management of Lei bamboo forests. Mulching with straw has not only added more litterfall into total raw litterfall carbon pool (rawlitc in Fig. 2), but also enhanced soil temperature (T-soi in Fig. 2) in Winter. So in IBIS model we modified biogeochemistry moudle. As organic mulching, $4 \mathrm{~kg} \mathrm{~m}^{-2} \mathrm{yr}^{-1}$ of carbon was added into total raw litterfall pool. And we assume that soil temperature rose $5^{\circ} \mathrm{C}$ abase on some previous researches (Qg et al. 1995; Huang et al. 2007; Zhang et al. 2013). The increasing of litterfall and soil temperature facilitated litter decomposition and soil respiration as Eqs. (5) and (8).

\subsection{Input Data}

If we want to compare the simulated result to the flux tower, we need provide the real meteorological to IBIS model. When the flux tower is working, temperature and precipitation data are recorded at the same time. However the flux tower only works for one year. The pre-heat of IBIS model and history simulation need meteorological data with long time scale. In our research, the data of pre-heat the IBIS model is using the average value of more than 700 meteorological sites from 1950 - 2006. We interpolate points data into a raster map than extract the data where the flux tower located in. Soil data is extracted from 1:1 million soil database. The simulation is derived by CGCM4 (Coupled General Circulation Model 4) simulated meteorological data in the history simulation.

\subsection{Experiment}

Flux tower measurement began in 2010. Measured variables used by IBIS model include $\mathrm{CO}_{2}$ flux, surface air temperature and precipitation. Other variables were not analyzed in this study.

IBIS simulation was from 1901 - 2010. Simulation pre-heat time consisted of two phases. First phase was from 1901 - 1949. In that time, the multi-year average states of atmosphere, vegetation and soil were used to driven IBIS modle and make modle equilibrium. The second phase was from 1950 - 2009. Due to the effects of climate change on the carbon cycle was significant, we used monthly meteorological data derived from CGCM4 simulation results to driven model simulation in order to make model state closer to real situation. From 2010, we use real meteorological data recorded from flux tower to simulate the carbon budget in the Lei bamboo forest. However, we only had one year observated meteorological data. Too short simulation time will increase the uncertainty of the results. So we had used meteorological data repeatedly and had done 10 simulations in 2010. And then 10-time averaged simulation outputs were used to evaluate model performance.

Futher more, in order to evaluate effects of cultivative managements on Lei bamboo forests carbon budget, we had designed two groups of simulations. One was used different fertilization level, the other was used different organic mulching level. Some detials setting were listed in Table 1 and 2.

\section{RESULTS}

\subsection{Model Validation}

The modifications had affected the carbon and nitrogen cycling in IBIS model. The outputs of IBIS model need some validations to verify the reasonableness of the modifications. Ground convering in winter had increased litterfall which impacted on soil carbon pool directly. At mean while, the shoot harvest and thinning had reduced the biomass of Lei bamboo forests. Moreover, including fertilization, all the managements had an effect on NPP and NEP. So the valudation had been done for these outputs by comparing with some previous studies and flux tower measurement and the results was shown in Table 3.

The sumulated average soil carbon is $13.33 \mathrm{~kg} \mathrm{~m}^{-2}$, which is consistent with some previous researches (Zhuang 
Table 1. Fertilization experiment.

\begin{tabular}{cccc}
\hline ID & Jan. & Jun. & Oct. \\
\hline F1 & Nm + N_uptake & Nm + N_uptake & Nm + N_uptake \\
F2 & Nm & Nm & Nm \\
F3 & Nm $+0.5 \times$ N_uptake & Nm $+0.5 \times$ N_uptake & Nm $+0.5 \times$ N_uptake \\
\hline
\end{tabular}

Note: $N m$ is the available nitrogen in soil; $N \_$uptake is the nitrogen absorbed by the plant physiological process.
Table 2. Soil temperature increasing experiment $\left({ }^{\circ} \mathrm{C}\right)$.

\begin{tabular}{llll}
\hline ID & Dec. & Jan. & Feb. \\
\hline $\mathrm{T} 1$ & +3 & +3 & +3 \\
$\mathrm{~T} 2$ & +1.5 & +1.5 & +1.5 \\
$\mathrm{~T} 3$ & +0 & +0 & +0 \\
\hline
\end{tabular}

Table 3. Yearly results compare with other researches.

\begin{tabular}{|c|c|c|c|c|c|}
\hline Name & IBIS Model & Other Research & Unit & Method & Reference \\
\hline Soil Carbon & $13.33 \pm 0.23$ & 13.9 & $\mathrm{kgC} \mathrm{m} \mathrm{m}^{-2}$ & Measurement & Zhuang et al. 2011) \\
\hline \multirow[t]{2}{*}{ Carbon in Biomass } & $2.56 \pm 0.05$ & 3.06 & $\mathrm{kgC} \mathrm{m}^{-2}$ & Measurement & Zhou and Jiang 2004 \\
\hline & & 3.14 & & Inventory Data & Fang et al. 1998 \\
\hline \multirow[t]{3}{*}{ NPP } & $0.79 \pm 0.02$ & $0.62-1.05$ & $\mathrm{kgC} \mathrm{m}^{-2} \mathrm{a}^{-1}$ & Inventory Data & Fang et al. 1998 \\
\hline & & $1-1.8$ & & Measurement & Koike 2001 \\
\hline & & 0.79 & $\mathrm{kgC} \mathrm{m}^{-2} \mathrm{a}^{-1}$ & BEPS model & Jiang et al. 2008 \\
\hline NEP & $0.41 \pm 0.02$ & 0.45 & $\mathrm{kgC} \mathrm{m}^{-2} \mathrm{a}^{-1}$ & Flux tower & This research \\
\hline
\end{tabular}

et al.2011). In those researches soil carbon content had been measured actually and the results show that the 15 years average soil carbon content is $13.9 \mathrm{~kg} \mathrm{~m}^{-2}$ in the Lei bamboo forest with organic mulching in winter which is close to our simulated soil carbon.

Few researches focus on biomass of Lei bamboo forests. However, the biomass of other bamboo forests had already been reported. Some researches had indicated that the carbon in biomass was $3.06 \mathrm{~kg} \mathrm{~m}^{-2}$ in mao bamboo forests (Zhou and Jiang 2004). And the other researchers had concluded from China forest inventory data that average biomass of China bamboo forest was $6.27 \mathrm{~kg} \mathrm{~m}^{-2}$, for another words, the carbon store in the biomass was $3.14 \mathrm{~kg} \mathrm{~m}^{-2}$ (Fang et al. 1998). In our research, we simulated carbon storage in biomass was $2.56 \mathrm{~kg} \mathrm{~m}^{-2}$. Because of the mao bamboo is one species with sturdy body and high carbon sequestration efficiency, its biomass is probably more than Lei bamboo's. Futher more, the shoots harvesting and thinning have a negative impact on biomass accumulation. So our research results have some reasonable aspects.

The yearly average NPP of Lei bamboo forest, simulated from IBIS model, was $0.93 \mathrm{kgC} \mathrm{m}^{-2} \mathrm{yr}^{-1}$. Pervious researching on NPP of bamboo forests usually through forests inventory data or model simulation. According to forests inventory data, the average bamboo NPP was $0.62-1.05 \mathrm{~kg} \mathrm{~m}^{-2} \mathrm{yr}^{-1}$ in south of China (Fang et al. 1998). And in Pearl River Delta in China, the bamboo forest NPP had been reported as $0.74 \mathrm{kgC} \mathrm{m}^{-2} \mathrm{yr}^{-1}$ in Pearl River Delta in China (Yang and Guan 2008). And a research in Japan had indicated that bamboo forest is about $1-1.8 \mathrm{~kg} \mathrm{~m}^{-2} \mathrm{a}^{-1}$ of carbon (Koike et al.
2001). While the simulated research on bamboo NPP in Fujian Province shown that the average NPP is $0.79 \mathrm{kgC} \mathrm{m}^{-2} \mathrm{yr}^{-1}$ using BEPS model (Jiang et al. 2008). Our NPP result is in the range of previous researches. And the yearly average NEP simulated result is $0.41 \mathrm{~kg} \mathrm{~m}^{-2} \mathrm{a}^{-1}$ of carbon. Due to the research on bamboo NEP is rare, we can only compare our simulated NEP with the measurement of flux tower. And a good consistency can be found in comparasion.

In summer, validation results are satisfactory. The modifications had make IBIS model simulate the growth of Lei bamboo forests more accurately.

\subsection{Carbon Cycling in Lei Bamboo Forests}

IBIS model shows good performance on average monthly NEP. The significance test results had been shown that our simulation results and observed data had no evidence difference $(\mathrm{p}<0.01)$. The accurate simulation reflected some characteristic of Lei bamboo growth and cultivate management.

The average yearly NEP is $0.45 \mathrm{kgC} \mathrm{m}^{-2} \mathrm{yr}^{-1}$ and Lei bamboo forest was a carbon sink. Accroding to observation results from Chinese Ecosystem Research Network (CERN) in Qianyanzhou, the NEP of typical natural subtropical coniferous forest (masson pine forest) was $0.39 \mathrm{kgC} \mathrm{m}^{-2} \mathrm{a}^{-1}$ in 2003 (Gu et al. 2006). And the NEP in artificial masson pine forest ecosystem was from $0.48-0.52 \mathrm{kgC} \mathrm{m}^{-2} \mathrm{a}^{-1}$ (Wang et al. 2010). Comparing these perious results, we can concluded that the NEP of cultivative Lei bamboo forest is higher than natural masson pine forest and closer to the artificial one. 
We found that Lei bamboo have two growing seasons in one year abase on average monthly change of NEP shown in Fig. 3a. The first growing season is March, April and May. The germination of new leaf and the improvement of growing environment make the rate of photosynthesis rise rapidly. After this period, the time is move to summer. Temperature and light become the limited factors to photosynthesis. And the level of NPP decline evidently shown in Fig. 3a. And then second growing season is following. From October, NPP increase again. Bamboo forest also have the fast growing in autumn such as some typical temperate tree species. In winter month, the rate of photosynthesis is weak. So the NPP decline. The highest NPP appear in the March or April, and the value is about $0.1 \mathrm{~kg} \mathrm{~m}^{-2} \mathrm{a}^{-1}$ of carbon. However the lowest NPP almost appear in the December and the value is $0.03 \mathrm{~kg} \mathrm{~m}^{-2} \mathrm{a}^{-1}$ of carbon.

The summit of NEP is appeared in October or November. High NEP in that time indicates that Lei bamboo is store carbon in its body. Considered with the growth characteristics of bamboo, carbon absorbed by bamboo may store in the bamboo rhizome for the bamboo shoots germinating in the coming year. And NEP is negative in the December, January, and February. The organic mulching in Winter took negative effects on NEP. It made temperature rise in the soil. So the decomposition rate and heterotrophic respiration are enhanced. As the same time, in the decomposition process of straw, respiration of microbe release lots of $\mathrm{CO}_{2}$ into the air. Additional, NPP is low in winter month. So the NEP appears negative value.

\subsection{Effect Of Fertilization and Organic Mulching}

In order to evaluate effects of fertilization and organic mulching on bamboo carbon cycling, two groups simulations had been set Table 1 and 2 .

As different types of fertilizers was used in fertilizations, it was difficult to estimate how many nitrogen turned into soil nitrogen pool. So we supplied nitrogen as the nitrogen was uptook by vegetation in different levels (details is in Table 1). And then, fertilization effects can be evaluated. Fertilization experiments results are shown in Fig. 4a. In January, as the bamboo forest has not enter the growing season, more nitrogen input into soil will accelerate decomposition process. So NEP declined as fertilizer levels increased. When growing season coming in February, fertilization will make the NEP increase rapidly. By comparing the experiments results, we conclude that fertilization made grow season coming earlier. Without fertilization, NEP will reach the top in April (F2). However, in fertilization simulation, the maximum NEP in spring will be appear in March (F1). Fertilization in June facilitates the growing of bamboo forest in summer. And in autumn when another growing
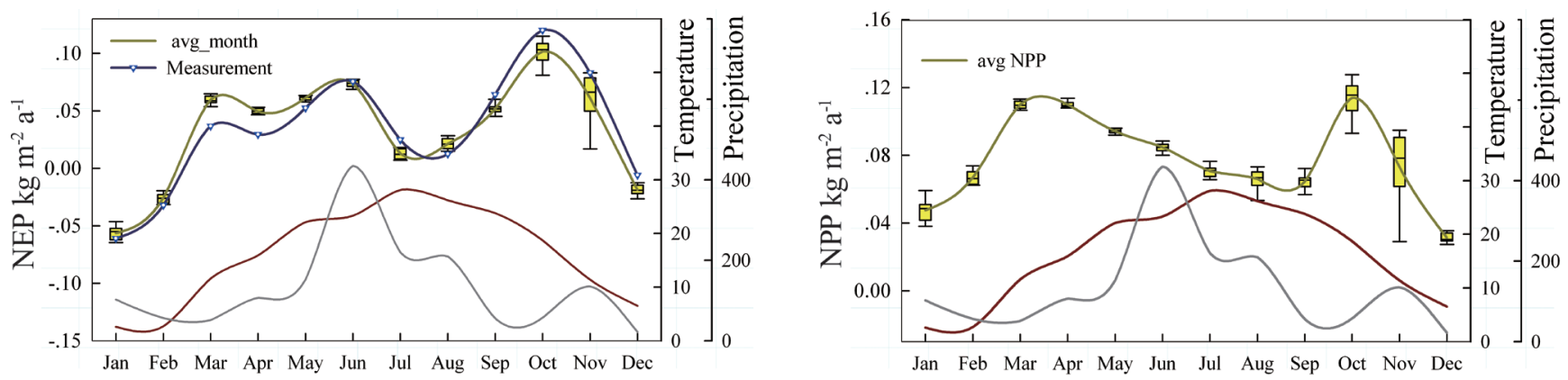

Fig. 3 Monthly variations of NEP and NPP. Red line and gray line represent temperature and precipitation respectively.

(a)

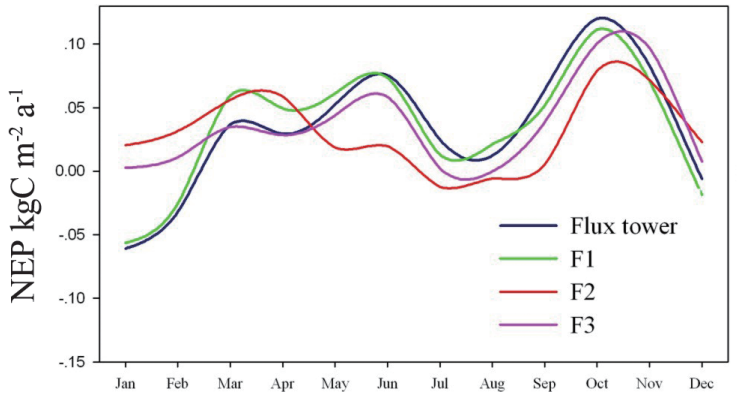

(b)

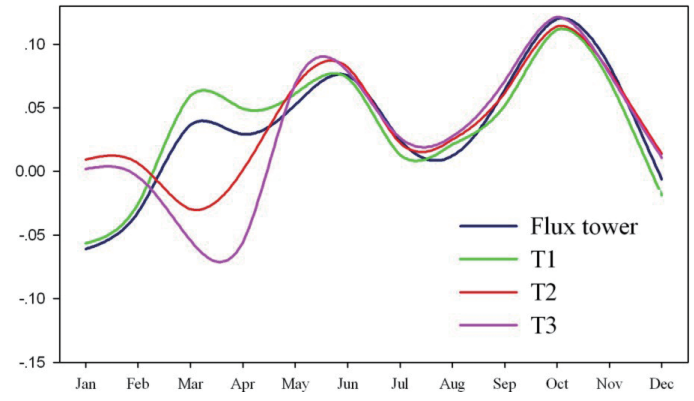

Fig. 4. The effect of fertilization and organic mulching. (a) NEP change under different fertilizations. F1, F2, and F3 is different fertilizer levels and detials are listed in Table 1; (b) NEP change under different soil temperature in winter. T1, T2 and T3 are different different soil temperature increase levels after organic mulching and detials are listed in Table 2. 
peak was coming, the demanding for nitrogen was urgent. In that season, carbon assimilation need more nitrogen support. Fertilization had take more positive effects on NEP. In winter, more fertilization input had taken more respiration which make the decline of NEP more evidence. In general fertilization takes positive effects on NEP in bamboo forests. Without fertilization, our simulated NEP can not matching observation and NEP was decline nearly $50 \%$.

Orgnic mulching increased soil temperature in Winter. As the soil temperature both takes effect on NPP [Eq. (2)] and soil respiration [Eq. (4)], it also influences NEP [Eq. (3)]. We set another group of simulations in order to find out how the organic mulching in winter takes effect on NEP. In IBIS model, we set soil temperature increasing in December, January, and February. More details of this group simulation are listed in Table 2.

The experiments results had shown that organic muchling not only made the growing season of bamboo forests come earlier, but also took positive effects on NEP. Comparing with T3 experiment where no soil temperature risen, NEP had risen up rapidly after February in the T1 and $\mathrm{T} 2$ experiments where soil temperature risen $5^{\circ}$ and $2.5^{\circ} \mathrm{C}$ respectively. So organic mulching is important to Lei bamboo shoots harvest earlier. After spring, NEP of each group is similar, without significant difference. In aspect ofcarbon sequestration, average NEP of T1 is $0.45 \mathrm{~kg} \mathrm{~m}^{-2} \mathrm{a}^{-1}$ and T3 is $0.37 \mathrm{~kg} \mathrm{~m}^{-2} \mathrm{a}^{-1}$, increasing about $21 \%$.

\section{DISCUSSION}

\subsection{Organic Mulching Influence Carbon Budget in Lei Bamboo Forest}

Concluded from simulated resluts, organic mulching facilitated carbon sequestration in bamboo forests. As the basic cultivative management, orgainic mulching in Winter took effects on NEP in two contradictory aspects. On one side, soil resipitration had been enhanced after organic mulching. The increased soil temperature took positive effects on decomposition rate of microbe and soil water content. And on the other side, organic mulching had made more carbon and nitrogen turn into soil during the process of mulching decomposition. As fertilizers, carbon and nitrogen stored in soil can promote the growth of Lei bamboo in the next spring. In winter, the photosynthesis is low, the increasing of resipiration weaken NEP obviously. But in sprint, as the growing season coming, plenty of nutrients had made Lei bamboo assimilate more carbon from atmosphere and sink it in ecosystem. In this season, the effects of organic mulching take more postive effects on Lei bamboo forest NEP. And from the view of the whole year, organic mulching pay more positive contribute to carbon sequestration. However, some researches had been indicated that organic mulching can make soil acidification seriously after multi-year intensive management, And then Lei bamboo forest degradation had occurred (Hong 2006; Sun et al. 2009). In the process of degradation of bamboo, carbon sequestration had been weaken gradually. So the effects of organic mulching is a complex process on carbon budget in Lei bamboo forest and need us to do some deeply researches.

\subsection{Analysis of IBIS Simulated Results}

The simulation accuracy was different in different time resolution. From the yearly averaged results, Lei Bamboo forests' NEP is similar to measurement of flux tower. It shows the good performance of IBIS model on yearly scale. But from the monthly averaged results (Fig. 4b), the NEP results from modified IBIS model can generally reflect the tendency of carbon sequestration change, but the NEP in spring and autumn were both not met actual value. It can be found that some features points of growth of Lei bamboo forests can not be reflected by IBIS model.

In spring, the simulated results was higher than observation. The growth features of Lei bamboo forests in spring are the growthing and havesting of shoots and the fast increment of LAI. Although the new carbon pool cpstore was designed to dicribe growth feature in spring, the modifications were accroding to some assumptions. Reasonableness of these assumptions still need further improvement. We had not difined bamboo shoot in IBIS model and the carbon of shoot harvsting was removed from cpstore directly. But in fact, the harvsting only removed above ground biomass of bamboo shoots. The part of below ground biomass will be decompose which will make heterotrophic respiration $(\mathrm{Rh})$ up and NEP down. Lacking of this process, the simulation and showed an envidence difference.

In autumn, the actual carbon sequestration in Lei bamboo is more than our simulation. In actually, bamboo forest get the highest NEP in autumn which is different from the common vegetation type. The reason can be contributed to the specific rhizome system below the bamboo stand. In each autumn, much carbon will move to and store in bamboo rhizome for fast growth in next year. Rhizome system is a huge system underground, but the carbon cycling of rhizome researche is rare. The role of rhizome can not be parameterized. So the function of rhizome was not incoporated into IBIS model. Ignoring the role of rhizome, our simulated results was lower than observation. And it aslo reflects that rhizome play an important role in bamboo forest carbon sequestration.

\subsection{Future Work and Prospect}

In summer, through the modification, IBIS model can simulate carbon cycling well, Although the growthing and harvesting of bamboo shoots, fertilization, organic mulching and thinning were incoporated into IBIS model which had made simulated results agree with flux tower observation, 
it still has some deficiencies in our simulation. The effects of harvesting bamboo shoot and rhizome on bamboo carbon cycles had not expressed well in IBIS model and futher improment of IBIS model should focus on this parts. In addition, the years with more bamboo shoots germination are appear alternately coupling with environment factors. In order to research effects of climate change on bamboo carbon cycling, bamboo shoot germination characteristics in the quantity also need to be reflected in the model. In the future, using IBIS modle we can scale up our site carbon cycling research results to Lei bamboo cultivation area and evaluate carbon budget in regional scale.

Acknowledgements Funding support partially from the NSF China Major Program (61190114 and 41171324) and The State Key Fundamental Science Funds of China (2011 CB302705, 2010CB950702, and 2010CB428503), The Funds for Ph.D. Education (20110091110028), The fundamental research project of MOST (2005DKA32300), The Priority Academic Program Development of Jiangsu Higher Education Institutions, Zhejiang province key science and technology innovation team (2010R50030).

\section{REFERENCE}

Chen, X., X. Zhang, Y. Zhang, T. Booth, and X. He, 2009: Changes of carbon stocks in bamboo stands in China during 100 years. For. Ecol. Manage., 258, 1489-1496, doi: 10.1016/j.foreco.2009.06.051. [Link]

Cleugh, H. A., R. Leuning, Q. Mu, and S. W. Running, 2007: Regional evaporation estimates from flux tower and MODIS satellite data. Remote Sens. Environ., 106, 285-304, doi: 10.1016/j.rse.2006.07.007. [Link]

Costa, M. H. and J. A. Foley, 2000: Combined effects of deforestation and doubled atmospheric $\mathrm{CO}_{2}$ concentrations on the climate of Amazonia. J. Climate, 13, 1834, doi: 10.1175/1520-0442(2000)013<0018:CEODA $\mathrm{D}>2.0 . \mathrm{CO} ; 2$. [Link]

Cox, P. M., R. A. Betts, C. D. Jones, S. A. Spall, and I. J. Totterdell, 2000: Acceleration of global warming due to carbon-cycle feedbacks in a coupled climate model. Nature, 408, 184-187, doi: 10.1038/35041539. [Link]

Cramer, W., A. Bondeau, F. I. Woodward, I. C. Prentice, R. A. Betts, V. Brovkin, P. M. Cox, V. Fisher, J. A. Foley, and A. D. Friend, C. Kucharik, M. R. Lomas, N. Ramankutty, S. Sitch, B. Smith, A. White, and C. YoungMolling, 2001: Global response of terrestrial ecosystem structure and function to $\mathrm{CO}_{2}$ and climate change: Results from six dynamic global vegetation models. Global Change Biol., 7, 357-373, doi: 10.1046/j.13652486.2001.00383.x. [Link]

Delire, C. and J. A. Foley, 1999: Evaluating the performance of a land Surface / ecosystem model with biophysical measurements from contrasting environments. J. Geophys.
Res., 104, 16895-16909, doi: 10.1029/1999JD900212. [Link]

E1 Maayar, M., D. T. Price, C. Delire, J. A. Foley, T. A. Black, and P. Bessemoulin, 2001: Validation of the Integrated Biosphere Simulator over Canadian deciduous and coniferous boreal forest stands. J. Geophys. Res., 106, 14339-14355, doi: 10.1029/2001JD900155. [Link]

Fang, J., G. G. Wang, G. Liu, and S. Xu, 1998: Forest biomass of China: An estimate based on the biomassvolume relationship. Ecological Applications, 8, 10841091, doi: 10.1890/1051-0761(1998)008[1084:FBOC AE]2.0.CO;2. [Link]

Farquhar, G. D. and T. D. Sharkey, 1982: Stomatal conductance and photosynthesis. Annu. Rev. Plant Physiol., 33, 317-345.

Foley, J. A., I. C. Prentice, N. Ramankutty, S. Levis, D. Pollard, S. Sitch, and A. Haxeltine, 1996: An integrated biosphere model of land surface processes, terrestrial carbon balance, and vegetation dynamics. Global Biogeochem. Cycles, 10, 603-628, doi: 10.1029/96GB02692. [Link]

Gu, F., M. Cao, X. Wen, Y. Liu, and B. Tao, 2006: A comparison between simulated and measured $\mathrm{CO}_{2}$ and water flux in a subtropical coniferous forest. Sci. China Ser.D, 49, 241-251, doi: 10.1007/s11430-006-8241-2. [Link]

Hong, Z. R., 2006: Allelopathy of cover planting on decline of phyllostachys praecox stand. Master Thesis, Chinese Academy of Forestry.

Huang, F., R. Cai, D. Sun, H. Qin, F. Yang, S. Zhuang, X. Lin, And Z. Cao, 2007: Soil nitrogen status and estimated nitrogen balance budget in an intensive managed Phyllostachys praecox stand. Plant Nutr. Fertilizer Sci., 13, 1193-1196.

Isagi, Y., T. Kawahara, K. Kamo, and H. Ito, 1997: Net production and carbon cycling in a bamboo Phyllostachys pubescens stand. Plant Ecol., 130, 41-52, doi: 10.1023/A:1009711814070. [Link]

Jiang, H., X. Q. Wang, W. J. Sun, and Q. M. Wang, 2008: Simulation and spatial-temporal analysis of forest net primary productivity in fujian province, China. In: Ehlers, M., K. Behncke, F. W. Gerstengarbe, F. Hillen, L. Koppers, L. Stroink (Eds.), Digital Earth Summit on Geoinformatics, Wichmann, Heidelberg, Germany, p. 290.

Jiang, P. K., Q. F. Xu, Z. H. Xu, and Z. H. Cao, 2006: Seasonal changes in soil labile organic carbon pools within a Phyllostachys praecox stand under high rate fertilization and winter mulch in subtropical China. For. Ecol.Manage., 236, 30-36, doi: 10.1016/j.foreco.2006.06.010. [Link]

Jin, A., B. Zheng, J. Tao, and D. Fang, 2000: Diurnal change of photosynthetic speed and its influential factors on Lei bamboo. J. Zhejiang Forestry Coll., 17, 271-275.

Ju, W. M., J. M. Chen, D. Harvey, and S. Wang, 2007: Future carbon balance of China's forests under climate 
change and increasing $\mathrm{CO}_{2}$. J. Environ. Manage., 85, 538-562, doi: 10.1016/j.jenvman.2006.04.028. [Link]

Kleinhenz, V. and D. J. Midmore, 2000: Estimating water usage of bamboo. Access to Asian Vegetables, 28, 1-2

Kleinhenz, V. and D. J. Midmore, 2001: Aspects of bamboo agronomy. Adv. Agron., 74, 99-153, doi: 10.1016/ S0065-2113(01)74032-1. [Link]

Koike, T., K. Sasa, and Y. Matsuura, 2001: A trial for evaluating $\mathrm{CO}_{2}$ fixation capacity in the plant communities of bamboo and dwarf bamboo. Sasa sp. Bamboo J., 18, 1-14. (in Japanese)

Kucharik, C. J., J. A. Foley, C. Delire, V. A. Fisher, M. T. Coe, J. D. Lenters, C. Young-Molling, N. Ramankutty, J. M. Norman, and S. T. Gower, 2000: Testing the performance of a dynamic global ecosystem model: Water balance, carbon balance, and vegetation structure. Global Biogeochem. Cycles, 14, 795-825, doi: 10.1029/1999GB001138. [Link]

Kunshan, S., L. Zhiyong, L. Fenming, and Z. Rui, 1997: China's country report on forestry. Asia-Pacific Forestry Towards 2010, Asia-Pacific Forestry Sector Outlook Study Working Paper Series.

Landsberg, J. and P. Sands, 2010: Physiological Ecology of Forest Production: Principles, Processes and Models, Academic Press, 352 pp.

Li, Y., P. Jiang, S. X. Chang, J. Wu, and L. Lin, 2010: Organic mulch and fertilization affect soil carbon pools and forms under intensively managed bamboo (Phyllostachys praecox) forests in southeast China. J. Soil. Sediment., 10, 739-747, doi: 10.1007/s11368-0100188-4. [Link]

Liu, J., D. T. Price, and J. M. Chen, 2005: Nitrogen controls on ecosystem carbon sequestration: A model implementation and application to Saskatchewan, Canada. Ecol. Model., 186, 178-195, doi: 10.1016/j.ecolmodel.2005.01.036. [Link]

Pan, Y., R. A. Birdsey, J. Fang, R. Houghton, P. E. Kauppi, W. A. Kurz, O. L. Phillips, A. Shvidenko, S. L. Lewis, J. G. Canadell, P. Ciais, R. B. Jackson, S. W. Pacala, A. D. McGuire, S. Piao, A. Rautiainen, S. Sitch, and D. Hayes, 2011: A large and persistent carbon sink in the world's forests. Science, 333, 988-993, doi: 10.1126/ science.1201609. [Link]

Pearson, A. K., O. P. Pearson, and I. A. Gomez, 1994: Biology of the bamboo Chusquea culeou (Poaceae: Bambusoideae) in southern Argentina. Vegetatio, 111, 93126, doi: 10.1007/BF00040331. [Link]

Qg, C., F. Sx, and H. Yx, 1995: Effect of different mulching materials on bamboo shoot production of Phyllostachys praecox stands. For. Sci.Res., 8, 39-43.

Ramankutty, N., J. A. Foley, J. Norman, and K. McSweeney, 2002: The global distribution of cultivable lands: Current patterns and sensitivity to possible climate change. Glob. Ecol. Biogeogr., 11, 377-392, doi: 10.1046/j.1466-822x.2002.00294.x. [Link]

Reichstein, M., P. Ciais, D. Papale, R. Valentini, S. Running, N. Viovy, W. Cramer, A. Granier, J. Ogée, V. Allard, M. Aubinet, Chr. Bernhofer, N. Buchmann, A. Carrara, T. Grünwald, M. Heimann, B. Heinesch, A. Knohl, W. Kutsch, D. Loustau, G. Manca, G. Matteucci, F. Miglietta, J. M. Ourcival, K. Pilegaard, J. Pumpanen, S. Rambal, S. Schaphoff, G. Seufert, J. F. Soussana, M. J. Sanz, T. Vesala, and M. Zhao, 2007: Reduction of ecosystem productivity and respiration during the European summer 2003 climate anomaly: A joint flux tower, remote sensing and modelling analysis. Global Change Biol., 13, 634-651, doi: 10.1111/j.13652486.2006.01224.x. [Link]

Scurlock, J. M. O., D. C. Dayton, and B. Hames, 2000: Bamboo: An overlooked biomass resource? Biomass Bioenerg., 19, 229-244, doi: 10.1016/S09619534(00)00038-6. [Link]

SFAPRC, 2005: Statistics of Forest Resources in China, 62.

Sun, X., S. Y. Zhuang, G. Q. Liu, G. D. Li, R. Y. Gui, and J. C. He, 2009: Effect of Lei Bamboo Plantation on Soil Basic Properties Under Intensive Cultivation Management. Soils, 41, 784-789.

Wang, Y., N. Zhang, and G. Yu, 2010: Simulation of carbon cycle in Qianyanzhou artificial masson pine forest ecosystem and sensitivity analysis of model parameters. Chin. J. Appl. Ecol., 21, 1656-1666.

Yang, K. and D. Guan, 2008: Changes in forest biomass carbon stock in the Pearl River Delta between 1989 and 2003. J. Environ. Sci., 20, 1439-1444, doi: 10.1016/ S1001-0742(08)62546-2. [Link]

Zhang, Y., P. Jiang, Y. Li, J. Wu, K. Xu, S. Hill, and H. Wang, 2013: Chemistry of decomposing mulching materials and the effect on soil carbon dynamics under a Phyllostachys praecox bamboo stand. J. Soil. Sediment., 13, 24-33, doi: 10.1007/s11368-012-0592-z. [Link]

Zhou, G. and P. Jiang, 2004: Density, storage and spatial distribution of carbon in Phyllostachy pubescens forest. Sci. Silvae Sinicae, 40, 20-24, doi: 10.11707/j.10017488.20040604. [Link]

Zhou, G., S. Zhuang, P. Jiang, Q. Xu, H. Qin, M. Wong, and Z. Cao, 2011: Soil organic carbon accumulation in intensively managed Phyllostachys praecox stands. Bot. Rev., 77, 296-303, doi: 10.1007/s12229-011-9071-2. [Link]

Zhu, Q., H. Jiang, J. Liu, X. Wei, C. Peng, X. Fang, S. Liu, G. Zhou, S. Yu, and W. Ju, 2010: Evaluating the spatiotemporal variations of water budget across China over 1951-2006 using IBIS model. Hydrol. Process., 24, 429-445, doi: 10.1002/hyp.7496. [Link]

Zhuang, S. Y., X. Sun, G. Q. Liu, M. H. Wong, and Z. H. Cao, 2011: Carbon sequestration in bamboo plantation soil with heavy winter organic mulching management. Bot. Rev., 77, 252-261, doi: 10.1007/s12229-0119081-0. [Link] 